\title{
(2) OPEN ACCESS \\ EML4-ALK positive lung adenocarcinoma with skeletal muscle metastasis in the right calf which was treatable with lorlatinib after resistance to treatment with alectinib
}

\author{
Hironari Matsuda, ${ }^{1}$ Munechika Hara, ${ }^{1}$ Shin-Ichiro Iwakami, ${ }^{1}$ Kazuhisa Takahashi ${ }^{2}$
}

\begin{abstract}
${ }^{1}$ Department of Respiratory Medicine, Juntendo Shizuoka Hospital, Izunokuni, Shizuoka, Japan

${ }^{2}$ Department of Respiratory Medicine, Juntendo University School of Medicine Graduate School of Medicine, Bunkyo-ku, Tokyo, Japan
\end{abstract}

Correspondence to Dr Hironari Matsuda; h-matsuda@juntendo.ac.jp

Accepted 6 April 2021

\section{SUMMARY}

This report concerns a patient with skeletal muscle metastases due to lung adenocarcinoma harbouring an echinoderm microtubule-associated proteinlike-4 (EML4)-anaplastic lymphoma kinase (ALK) rearrangement, who was successfully treated with lorlatinib after resistance to alectinib. A right lower lobectomy based on a diagnosis of lung adenocarcinoma was performed on a 77-year-old Japanese woman. After 7 months of surgical resection, a mass in the right calf was observed. A fine-needle aspiration biopsy from the mass was performed and the mass was diagnosed as metastatic adenocarcinoma harbouring EML4ALK rearrangement. Alectinib was administered for 10 months. Then, administration of lorlatinib, an ALK tyrosine kinase inhibitor classified as third generation, was initiated after resistance to treatment with alectinib. After starting treatment with lorlatinib, the gastrocnemius tumour diminished and has maintained a stable condition. Our case suggests that EML4-ALK positive lung adenocarcinoma is treatable with lorlatinib after resistance to treatment with alectinib.

\section{BACKGROUND}

Lung cancer is the major cause of cancer-related death, and it is generally known that lung cancer commonly spreads to other parts of the body, such as the brain, the bone and the liver and rarely metastasises to skeletal muscle. ${ }^{12}$ Skeletal muscle metastases (SMM) were mostly found in the trunk or upper limbs and rarely in the lower limbs. ${ }^{3}$ It is also said that the presence of SMM represents a higher risk of mortality. ${ }^{4}$ However, the mechanism of SMM is not clear.
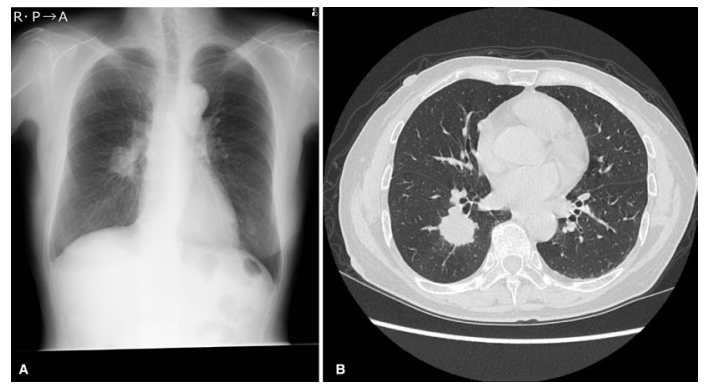

Figure 1 Chest X-ray showing a $39 \mathrm{~mm}$ solid mass in the right middle lung field (A). CT of the chest showing a $34 \times 26 \mathrm{~mm}$ solid mass in the 56 of the right lung (B).

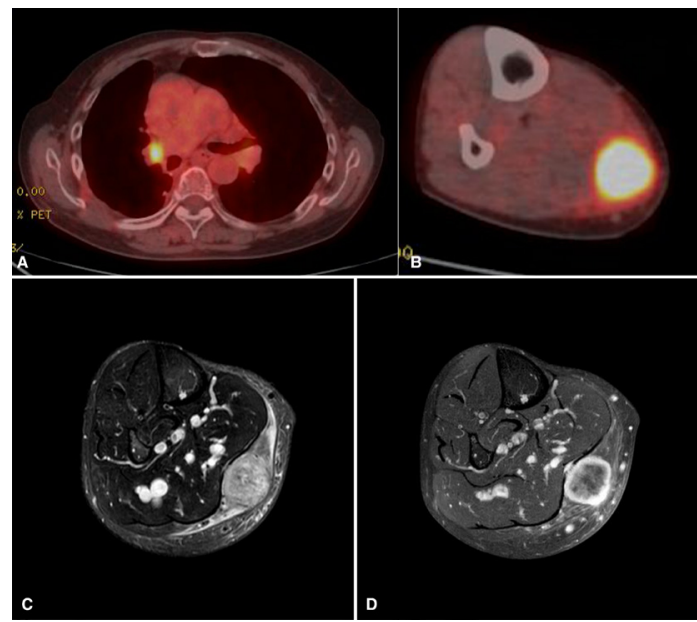

Figure 2 Positron emission tomography CT showing abnormal uptakes in the right lung hilar lymph node (A), the right popliteal lymph node and the right gastrocnemius (B). A contrast-enhanced MRI of the right leg showing a tumour in the gastrocnemius with heterogeneously high contrast on the T2 emphasised image (C) and the gadolinium enhanced the peripheral of the tumour (D).

Nowadays tyrosine kinase inhibitors have changed treatment strategies for advanced lung cancer. Echinoderm microtubule-associated protein-like-4 (EML4)-anaplastic lymphoma kinase (ALK) gene rearrangement is one of the driver mutations first reported in 2007..$^{5}$ ALK inhibitors have demonstrated good activity in patients with EML4-ALK positive non-small cell lung cancer (NSCLC). ${ }^{67}$ Lorlatinib is an ALK and c-ros oncogene 1 tyrosine kinase inhibitor classified as third generation and is expected to overcome ALK resistance mutations that can develop during treatment with ALK inhibitors classified as first or second generation. ${ }^{8}$

We report on a patient diagnosed as having EML4-ALK positive lung adenocarcinoma with skeletal muscle metastases in the lower leg who responded well to lorlatinib after showing resistance to treatment with alectinib.

\section{CASE PRESENTATION}

A 77-year-old woman was referred to our hospital because of an abnormal shadow in the right lower lung. Her medical history included postoperative thyroid papillary carcinoma when she was 71 . She 


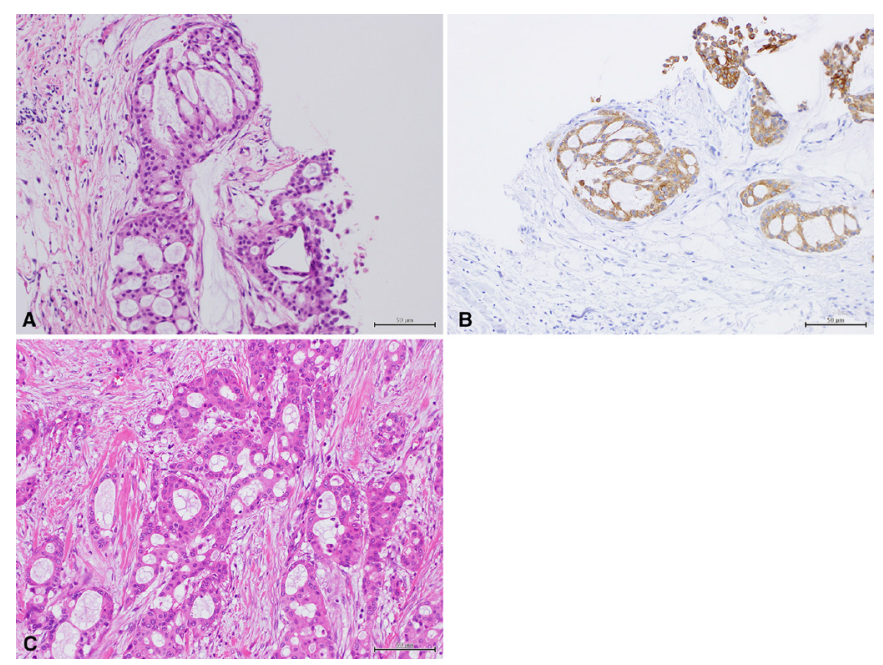

Figure 3 Histopathology slides obtained from the gastrocnemius tumour and the lung. H\&E stain exam $(\times 20)$ from the gastrocnemius tumour $(A)$ and the lung $(C)$. Immunohistochemistry studies $(\times 20)$ from the gastrocnemius tumour revealing diffused expression of cytokeratin 7 (B). Both H\&E stains from the gastrocnemius tumour (A) and the lung (C) revealing tumour cells with acinar pattern.

had no history of smoking. Chest X-ray revealed a solid tumour in the right middle lung field (figure 1A). Thoracic CT revealed a solid tumour in the lower lobe of the right lung (figure 1B). A right lower lung lobectomy was performed based on the diagnosis of lung adenocarcinoma in the right lower lobe without any distant metastasis (pT1cN1M0, stage IIB seventh edition). After the surgical resection, the patient was observed carefully without adjuvant chemotherapy. About 7 months after the operation, an elastic hard mass in the right calf causing pain was observed.

\section{INVESTIGATIONS}

The patient's routine complete blood count and chemical laboratory data were all within the normal range. Her carcinoembryonic antigen was normal $(3 \mathrm{ng} / \mathrm{mL})$, and her sialyl lewisX-i antigen was slightly elevated $(48.8 \mathrm{U} / \mathrm{mL})$. With concern regarding a relapse of the lung cancer, a positron emission tomography (PET)-CT was performed revealing an abnormal uptake in the right lung hilar lymph node, the right popliteal lymph node and the right gastrocnemius (figure 2A,B). Contrast-enhanced MRI of the right leg showed a tumour in the gastrocnemius on the T2 emphasised image, which was of heterogeneously high-signal intensity, with the rim of the tumour enhanced by the gadolinium (figure 2C,D). A fine-needle aspiration biopsy (FNAB) from the gastrocnemius tumour was performed. The specimen
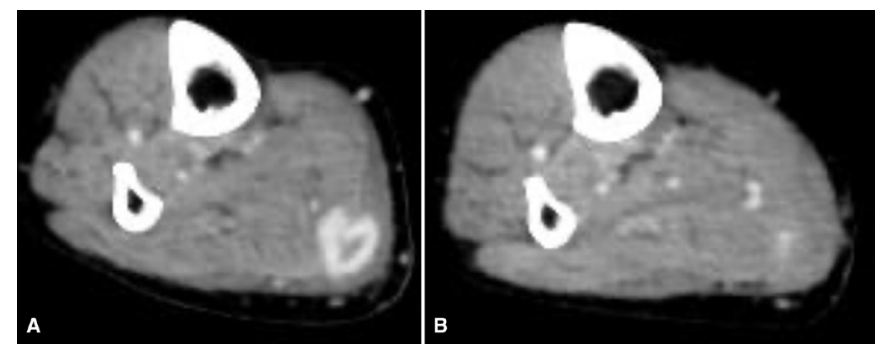

Figure 4 Enhanced CT showing the skeletal muscle metastases in the right leg before $(A)$ and after (B) 2 months of taking lorlatinib. The tumour exhibited a response with lorlatinib. obtained revealed moderately differentiated adenocarcinoma (figure 3A). Immunohistochemistry (IHC) studies revealed that diffused expression of cytokeratin 7 (CK7) (figure 3B), thyroid transcription factor-1 (TTF-1) was negative, whereas IHC of the primary lung tumour revealed expression of both of them. The primary lesion in the right leg tumour could not be clarified from the IHC stains. However, in the morphological feature of the primary lung cancer (figure 3C) and the leg tumour, both the H\&E stains showed an acinar pattern. Thus, the patient was diagnosed with relapsed lung adenocarcinoma. In addition, using IHC, it was proven that the primary lung cancer was harbouring EML4-ALK rearrangement.

\section{TREATMENT}

Alectinib (300 mg two times a day) was administered as the initial treatment, and the gastrocnemius tumour shrank in a month. After 10 months of treatment with alectinib, the gastrocnemius tumour increased in size with pain again. And in spite of two cycles of second-line therapy using pemetrexed, the disease could not be controlled. Lorlatinib (100 mg one time a day) was initiated as third-line therapy.

\section{OUTCOME AND FOLLOW-UP}

After initiating lorlatinib, the gastrocnemius tumour diminished within a month and has maintained a stable condition (figure 4). In 2 months of taking lorlatinib, dyslipidaemia (low density lipoprotein cholesterol $265 \mathrm{ng} / \mathrm{mL}$, triglyceridaemia $474 \mathrm{mg}$ / dL) developed as adverse events, treatable with rosuvastatin and bezafibrate. No other severe side effects have been revealed so far.

\section{DISCUSSION}

It is generally known that lung cancer commonly metastasises to other parts of the body. About 20\%-50\% of patients with NSCLC have metastases when lung cancer is diagnosed. ${ }^{9}$ The common sites of distant metastases are the brain (10\%), bone $(7 \%)$ and the liver $(5 \%) .^{2}$ Besides these organs, the skeletal muscle is one of the sites where NSCLC metastasises. SMM is a rare condition, estimated at $2.6 \%$ of NSCLC at the time of initial diagnoses. ${ }^{1}$ The presence of SMM is considered as a progressive condition. Pop et al reported that the median survival time of patients with lung cancer with SMM was 6 months. ${ }^{4}$ The reason for the rarity of SMM is still unclear, but there are several hypotheses, one of which suggests that muscle resists metastatic disease, such as mechanical, metabolic or immunological. None of these can explain the whole mechanism but in combination theorising may be possible. ${ }^{4}$

Most of the instances of SMM were accidentally diagnosed during routine CT, because a large proportion of patients with SMM are asymptomatic or neglected. ${ }^{1}$ There are several CT imaging patterns. It was reported that clinical symptoms such as severe pain or restriction of local movement tend to arise when SMM revealed a rim-enhanced tumour using enhanced CT. ${ }^{10}$ MRI is also a helpful technique for characterising soft tissue regions. Li et al reported that soft tissue sarcoma, single haematoma, haemangioma or malignant fibrous histocytoma can mimic SMM in MRI. ${ }^{11}$ Nevertheless, CT and MRI are sometimes not sufficient for screening all soft tissue tumours. PET-CT could provide additional diagnostic information to a greater extent than other staging examinations. ${ }^{12}$ Although the metastatic tumour was in the lower leg in this case, the trunk and upper limbs are common metastatic sites according to a systematic review relating muscle metastases. ${ }^{3}$ 
Biopsy is the most reliable test to confirm SMM. Trocar biopsy and FNAB are valid in order to distinguish carcinoma from other diseases. ${ }^{13}$ In the present literature, the most common histological diagnosis of SMM confirmed by FNAB was adenocarcinoma. ${ }^{14}$ Panel markers such as CK7 and CK20, and TTF-1 are necessary to detect the origin of a metastatic tumour. However, TTF-1 positivity is observed in $75 \%-80 \%$ of lung adenocarcinomas with sensitivity decreasing with poor differentiation as well as in mucinous adenocarcinoma. ${ }^{15}$

There are some treatment options for SMM such as radiotherapy, surgical excision and medication. SMM is sometimes painful and excision of the painful mass may help the patients. Local treatments of the mass might affect the rate of recurrence and survival time. ${ }^{14}{ }^{16}$ Tuoheti et al reported in a case series that a patient with lung cancer who underwent the excision of the muscle metastatic lesion was disease-free for 92 months and patients with some other cancer survived for an average of 18.5 months after radiation therapy. ${ }^{14}$

EML4-ALK gene rearrangement occurs in 3\%-5\% of NSCLC in East Asian countries. ${ }^{5} 17$ Mostly, ALK inhibitors are the preferred choice for advanced EML4-ALK positive NSCLC. Crizotinib and ceritinib have improved progression-free survival (PFS) compared with chemotherapy. ${ }^{6}{ }^{18}$ Then alectinib showed longer PFS than crizotinib (34.8 months with alectinib vs 10.9 months with crizotinib). ${ }^{6}$ Considering these facts, ALK inhibitors can be the appropriate choice for patients with EML4-ALK positive lung cancer with SMM.

Resistance mechanisms to ALK inhibitors depend on secondary mutation in the kinase domain or the variant type of ALK fusion. ${ }^{6}{ }^{1920}$ These mechanisms could be related to resistance to treatment with alectinib in our case. Furthermore, the shorter duration of response for alectinib might be connected to the aggressive state of the disease, such as the presence of SMM.

Lorlatinib is an ALK tyrosine kinase inhibitor classified as third generation with a multi-coverage of ALK kinase domain inhibitor. ${ }^{8}$ In the global phase 2 study, lorlatinib proved efficacious in patients with EML4-ALK positive lung cancer who had been treated with former generation ALK inhibitors such as alectinib or crizotinib. It was reported that $47 \%$ of patients previously treated with at least one ALK inhibitor improved clinically and their median PFS was 6.9 months. The median time for first tumour response was 1.4 months. ${ }^{8}$ Such a rapid response time and high response rate might be helpful for a patient with painful SMM.

\section{Learning points}

- This is the first report, to the best of our knowledge, of gastrocnemius muscle metastasis from echinoderm microtubule-associated protein-like-4 (EML4)-anaplastic lymphoma kinase (ALK) positive lung cancer treatable with lorlatinib.

- Our case suggests that lorlatinib is an option for EML4-ALK positive lung cancer after showing resistance to treatment with alectinib.

- It is important to obtain a proper pathological and genetic diagnosis from skeletal muscle metastases to provide appropriate treatments.
Finally, SMM from lung adenocarcinoma is a rare but aggressive condition. Lorlatinib is an effective choice for advanced EML4-ALK positive lung cancer after the failure of alectinib treatment with good tolerance. Furthermore, appropriate assessments of pathological and genetic diagnosis are important steps to provide better treatments.

Contributors HM created a large part of the article. MH was in charge of the outpatient clinic. HM and MH took charge of the patient who was hospitalised. S-II and KT proofread the article.

Funding The authors have not declared a specific grant for this research from any funding agency in the public, commercial or not-for-profit sectors.

Competing interests None declared.

Patient consent for publication Obtained.

Provenance and peer review Not commissioned; externally peer reviewed.

Open access This is an open access article distributed in accordance with the Creative Commons Attribution Non Commercial (CC BY-NC 4.0) license, which permits others to distribute, remix, adapt, build upon this work non-commercially, and license their derivative works on different terms, provided the original work is properly cited and the use is non-commercial. See: http://creativecommons.org/ licenses/by-nc/4.0/.

\section{REFERENCES}

1 Bocchino M, Valente T, Somma F, et al. Detection of skeletal muscle metastases on initial staging of lung cancer: a retrospective case series. Jpn J Radiol 2014;32:164-71.

2 Quint LE, Tummala S, Brisson LJ, et al. Distribution of distant metastases from newly diagnosed non-small cell lung cancer. Ann Thorac Surg 1996;62:246-50.

3 Lupi A, Weber M, Del Fiore $P$, et al. The role of radiological and hybrid imaging for muscle metastases: a systematic review. Eur Radiol 2020;30:2209-19.

4 Pop D, Nadeemy AS, Venissac N, et al. Skeletal muscle metastasis from non-small cell lung cancer. J Thorac Oncol 2009;4:1236-41.

5 Soda M, Choi YL, Enomoto M, et al. Identification of the transforming EML4-ALK fusion gene in non-small-cell lung cancer. Nature 2007;448:561-6.

6 Solomon BJ, Mok T, Kim D-W, et al. First-line crizotinib versus chemotherapy in ALKpositive lung cancer. N Engl J Med 2014;371:2167-77.

7 Camidge DR, Dziadziuszko R, Peters S, et al. Updated efficacy and safety data and impact of the EML4-ALK fusion variant on the efficacy of alectinib in untreated ALK-positive advanced non-small cell lung cancer in the global phase III ALEX study. J Thorac Oncol 2019;14:1233-43.

8 Solomon BJ, Besse B, Bauer TM, et al. Lorlatinib in patients with ALK-positive non-small-cell lung cancer: results from a global phase 2 study. Lancet Oncol 2018;19:1654-67.

9 Schuchert MJ, Luketich JD. Solitary sites of metastatic disease in non-small cell lung cancer. Curr Treat Options Oncol 2003:4:65-79.

10 Surov A, Hainz M, Holzhausen $\mathrm{H}-\mathrm{J}$, et al. Skeletal muscle metastases: primary tumours, prevalence, and radiological features. Eur Radiol 2010;20:649-58.

11 Li Q, Wang L, Pan S, et al. Skeletal muscle metastases on magnetic resonance imaging: analysis of 31 cases. Contemp Oncol 2016;20:242-50.

12 Abdel-Rahman 0, ElHalawani H, Fouad M. Risk of gastrointestinal complications in cancer patients treated with immune checkpoint inhibitors: a meta-analysis. Immunotherapy 2015;7:1213-27.

13 Molina-Garrido MJ, Guillén-Ponce C. Muscle metastasis of carcinoma. Clin Trans/ Oncol 2011;13:98-101

14 Tuoheti Y, Okada K, Osanai T, et al. Skeletal muscle metastases of carcinoma: a clinicopathological study of 12 cases. Jpn J Clin Oncol 2004;34:210-4.

15 Doxtader EE, Chute DJ. Evaluation of carcinoma of unknown primary on cytologic specimens. Surg Pathol Clin 2018;11:545-62.

16 Herring CL, Harrelson JM, Scully SP. Metastatic carcinoma to skeletal muscle. A report of 15 patients. Clin Orthop Relat Res 1998:272-81.

17 Rikova K, Guo A, Zeng Q, et al. Global survey of phosphotyrosine signaling identifies oncogenic kinases in lung cancer. Cell 2007;131:1190-203.

18 Soria J-C, Tan DSW, Chiari R, et al. First-line ceritinib versus platinum-based chemotherapy in advanced ALK-rearranged non-small-cell lung cancer (ASCEND-4): a randomised, open-label, phase 3 study. Lancet 2017;389:917-29.

19 Gainor JF, Dardaei L, Yoda S, et al. Molecular mechanisms of resistance to first- and second-generation ALK inhibitors in ALK-rearranged lung cancer. Cancer Discov 2016:6:1118-33

20 Lin JJ, Zhu VW, Yoda S, et al. Impact of EML4-ALK variant on resistance mechanisms and clinical outcomes in ALK-positive lung cancer. J Clin Oncol 2018;36:1199-206. 
Copyright 2021 BMJ Publishing Group. All rights reserved. For permission to reuse any of this content visit https://www.bmj.com/company/products-services/rights-and-licensing/permissions/

BMJ Case Report Fellows may re-use this article for personal use and teaching without any further permission.

Become a Fellow of BMJ Case Reports today and you can:

- Submit as many cases as you like

- Enjoy fast sympathetic peer review and rapid publication of accepted articles

- Access all the published articles

- Re-use any of the published material for personal use and teaching without further permission

Customer Service

If you have any further queries about your subscription, please contact our customer services team on +44 (0) 2071111105 or via email at support@bmj.com.

Visit casereports.bmj.com for more articles like this and to become a Fellow 